\title{
A DIVISÃO DOS CUIDADOS SOCIAIS PRESTADOS A PESSOAS IDOSAS Complexidades, desigualdades e preferências
}

\author{
José de São José \\ Faculdade de Economia da Universidade do Algarve, Faro, Portugal
}

\section{Introdução}

Este artigo foca-se na divisão dos cuidados sociais prestados a pessoas idosas entre os cuidadores familiares e os cuidadores não familiares. Através do uso de instrumentos concetuais que vão para além das concetualizações dicotómicas usadas na investigação já realizada sobre este tema, este artigo tem como objetivo dar conta das formas como os cuidadores familiares dividem os cuidados com os cuidadores não familiares, das vantagens e desvantagens que os primeiros atribuem às respetivas formas de divisão, e das suas perspetivas relativamente à futura divisão dos cuidados. Os resultados mais relevantes - do ponto de vista sociológico, das práticas profissionais e das políticas sociais - são discutidos de uma forma aprofundada.

Ao longo das últimas décadas tem-se assistido, no mundo ocidental, a uma tendência no sentido de uma maior combinação entre cuidados familiares e cuidados não familiares prestados a pessoas idosas (Huber e outros, 2009). A expansão do chamado welfare mix, no que respeita aos cuidados sociais ${ }^{1}$ destinados à população idosa, tem levado a um crescimento do número de investigações sobre a interconexão entre os diferentes modos de provisão destes cuidados (cuidados providos pela família, pelo estado, pelo mercado e pelo terceiro setor). ${ }^{2}$

Existem diversos estudos que, a partir de uma perspetiva societal ou macrossocial, se focam sobre os regimes de prestação de cuidados sociais (social care regimes), estudos estes iniciados pelo trabalho pioneiro de Anttonen e Sipilä (1996). Têm sido propostas diferentes tipologias de social care regimes, ${ }^{3}$ a maior parte destas focando-se na interconexão entre a família e o estado (ver Anttonen e Sipilä, 1996; Leitner, 2003; Saraceno e Keck, 2010), embora haja uma minoria que engloba outros setores de provisão, como por exemplo o mercado informal (ver Bettio e Plantenga, 2004; Lyon and Glucksmann, 2008). Portugal aparece nalgumas destas tipologias, sendo a tipologia proposta por Leitner (2003) a que nos parece mais acertada para caracterizar a situação de Portugal no que toca às

1 Os cuidados sociais excluem normalmente os cuidados de saúde, embora se reconheça que esta distinção não é pacífica. Os cuidados sociais incluem a realização de tarefas tais como ajudar na higiene corporal, ajudar a comer, ajudar a vestir e a despir, ajudar na compra e na toma dos medicamentos, ajudar na gestão de assuntos administrativos, entre outras tarefas.

2 Normalmente entende-se que o terceiro setor é constituído por instituições particulares de solidariedade social e instituições equiparadas.

3 O termo social care regimes refere-se, basicamente, à forma de organização da provisão de cuidados sociais (em termos de serviços e de outros benefícios sociais) e à cultura que lhe está subjacente. 
políticas sociais direcionadas para os cuidados à população idosa. De acordo com esta tipologia, Portugal insere-se no grupo de países onde vigora um "familiarismo implícito", que se caracteriza por uma baixa oferta de serviços sociais e por um sistema rudimentar de licenças para prestar cuidados, e de prestações sociais diretas e indiretas para compensar os custos do cuidar. Este "familiarismo implícito" reproduz as desigualdades de género na prestação de cuidados familiares, as quais desfavorecem as mulheres.

Por seu lado, outros estudos, a partir de uma perspetiva microssocial, focam-se na compreensão da natureza da articulação entre vários tipos de cuidadores. Alguns focam-se na articulação entre os serviços públicos e os cuidadores familiares, enquanto outros se focam na articulação entre cuidadores formais e cuidadores informais (cuidadores que prestam cuidados fora de um enquadramento institucional). Os primeiros estudos procuram esclarecer se os cuidados públicos fazem reduzir os cuidados familiares ou se, pelo contrário, fazem com que estes se mantenham ou até se reforcem (ver, p. ex.: Arber e Attias-Donfut, 2000; Motel-Klingebiel e outros, 2005). Por sua vez, os segundos estudos preocupam-se sobretudo em verificar se a articulação entre os cuidadores informais e os cuidadores formais assenta em processos de "substituição" ou de "complementaridade" (ver, p. ex.: Chappell e Blandford, 1991; Litwin e Attias-Donfut, 2009).

Os estudos anteriormente referidos, tanto os que adotam uma perspetiva macro com os que adotam uma perspetiva micro, contribuem indiscutivelmente para um melhor conhecimento da interconexão entre diferentes modos de provisão de cuidados sociais para pessoas idosas. Contudo, trata-se de uma investigação marcada (embora de uma forma mais notória nuns casos do que noutros) por diferentes dicotomias que dificultam a apreensão da diversidade e da complexidade que possam existir neste domínio da realidade social. De entre as diversas dicotomias destacam-se as seguintes: cuidados informais/cuidados formais; substituição/complementaridade (substitution/complementary ou crowding out/crowding in); desfamiliarização/familiarização (de-familialisation/familialisation); e desmercadorização/mercadorização (de-commodification/commodification).

A primeira dicotomia é a mais utilizada e encontra-se nos estudos conduzidos por Anttonen e Sipilä (1996), Bettio e Plantenga (2004), e em praticamente todos os estudos que usam a dicotomia "substituição/complementaridade". Esta dicotomia assume que os cuidados informais não são pagos e que os cuidados formais são pagos, mas isto nem sempre corresponde à realidade. Por vezes os cuidados informais são pagos (por exemplo, cuidadores familiares que recebem subsídios do estado, ou cuidadores não familiares que prestam cuidados fora de qualquer enquadramento institucional mas que recebem um pagamento pelos cuidados prestados), e os cuidados formais não são pagos (por exemplo, trabalho de voluntariado enquadrado por uma instituição). A este respeito, Geissler e Pfau-Effinger (2005) chamam a atenção para a emergência de duas novas formas de cuidados informais que se distinguem dos cuidados informais tradicionais (não pagos): semiformal family care (cuidadores familiares que são subsidiados pelo estado) e informal care employment (pessoas que prestam cuidados fora de qualquer enquadramento institucional e que recebem um pagamento pelos cuidados prestados). 
A segunda dicotomia encontra-se nos estudos que procuram compreender a natureza da interconexão entre diferentes tipos de cuidadores. Temos estudos mostrando que os cuidadores formais substituem gradualmente os cuidadores informais (substitution), ou que os cuidados prestados por entidades públicas substituem os cuidados familiares (crowding out). Num polo oposto, temos estudos demonstrando que a articulação entre cuidadores formais e informais se baseia na complementaridade (complementary), ou que a articulação entre cuidados públicos e cuidados familiares se baseia também na complementaridade (crowding in). No âmbito destes estudos, a "substituição" e a "complementaridade" têm sido apresentadas como processos mutuamente exclusivos. Contudo, estes podem coexistir, por exemplo, quando os cuidadores informais podem ser substituídos pelos cuidadores formais na realização de uma determinada tarefa de cuidar, mas a natureza da interconexão entre os diferentes tipos de cuidadores se mantém baseada na complementaridade. Por outro lado, um forte envolvimento de cuidadores formais na prestação de cuidados não implica, necessariamente, uma substituição total dos cuidadores familiares, pois estes podem canalizar os seus esforços para tarefas de supervisão/monitorização dos cuidados prestados por terceiros e para a prestação de cuidados de natureza emocional.

A terceira e a quarta dicotomias encontram-se essencialmente nos estudos que se focam na divisão societal dos cuidados sociais. A terceira dicotomia ("desfamiliarização"|"familiarização") remete para a "relação de forças" entre cuidados familiares e cuidados não familiares, e encontra-se, por exemplo, no estudo conduzido por Saraceno e Keck (2010). O processo de "desfamiliarização" implica uma transferência da prestação de cuidados dos familiares para cuidadores não familiares, enquanto o processo de "familiarização" se traduz no processo inverso. Estes constructos, embora possam ser apresentados como constituindo dois polos de um continuum, também colocam algumas limitações heurísticas, pois nem sempre uma forte participação de cuidadores não familiares significa uma "desfamiliarização" dos cuidados. Por exemplo, uma empregada doméstica que está disponível 24 horas por dia para prestar cuidados, dormindo inclusivamente na casa do idoso, pode ser tratada pelo idoso (e também pelos seus familiares) como se fosse da família, e agir, na prática, enquanto tal. Assim, neste exemplo, é mais adequado falar-se em "familiarização" de cuidados não familiares e não tanto de "desfamiliarização".

Por último, a dicotomia "desmercadorização"/"mercadorização" aparece nalgumas discussões sobre os "regimes de cuidados sociais" para pessoas idosas (ver Ungerson, 2003). A "desmercadorização" dos cuidados traduz-se num processo de redução do elemento monetário na prestação de cuidados, ao passo que a "mercadorização" implica precisamente o inverso. Estes dois constructos também podem funcionar como dois polos de um continuum, no entanto uma solução de prestação de cuidados aparentemente "mercadorizada" pode conter elementos que vão para além de uma relação de pura "compra e venda" de serviços. O exemplo da empregada doméstica atrás descrito mostra-nos que a relação entre o idoso (e os seus familiares) e a empregada doméstica "rompe" com os formalismos típicos de uma relação "mercadorizada". 
Assim, podemos concluir que estas dicotomias não são suficientemente dúcteis para captar, sobretudo num plano micro, as complexas interconexões entre os diferentes provedores de cuidados sociais. Para além disto, interessa acrescentar que os estudos já realizados que se focam no plano micro da divisão dos cuidados não identificam rigorosamente o tempo (número de horas) que os diferentes cuidadores dedicam à prestação de cuidados nem o tipo de tarefas de cuidar que realizam. Se queremos captar a forma como os diferentes tipos de cuidadores dividem os cuidados prestados às pessoas idosas, é fundamental saber que tipo de tarefas é que cada cuidador presta e a quantidade de tempo que aloca à prestação dessas tarefas. Para além disto, os estudos focados no plano micro negligenciam os significados que os cuidadores atribuem às diferentes formas de divisão dos cuidados. Ora, é verosímil que idênticas formas de divisão de cuidados possam ter diferentes significados para os cuidadores intervenientes. Importa ainda referir que os contextos nos planos meso e macro sob os quais a (micro)divisão dos cuidados decorre nem sempre têm sido considerados por estes estudos.

\section{A investigação}

\section{Dados empíricos}

Os resultados apresentados neste artigo fazem parte de um conjunto mais vasto de dados que foram obtidos através de uma investigação empírica qualitativa realizada na região de Lisboa entre 2005 e 2009 (ver São José, 2009). Esta investigação debruça-se sobre os cuidados familiares prestados a pessoas idosas, dando conta, no plano microssocial, de diversas dimensões destes cuidados, entre as quais a divisão da provisão dos cuidados entre os cuidadores familiares, de um lado, e os cuidadores não familiares, de outro lado (e não tanto da divisão dos cuidados no interior de cada um destes grupos). Para além das diversas formas de divisão dos cuidados, também evidencia as vantagens e as desvantagens que lhes são atribuídas pelos cuidadores familiares, bem como a divisão de cuidados que estes últimos perspetivam para o futuro.

\section{Instrumentos concetuais}

Neste artigo propomos um modelo concetual que pretende evitar as concetualizações dicotómicas anteriormente revistas. O modelo proposto inspira-se nos trabalhos de Miriam Glucksmann no domíno da sociologia do trabalho (Glucksmann, 2005; Lyon e Glucksmann, 2008), bem como nos trabalhos de alguns autores no domínio dos cuidados sociais para pessoas idosas, nomeadamente nos trabalhos de Mary Daly e Jane Lewis (2000). Retiram-se dois elementos essenciais destes trabalhos. Em primeiro lugar, a definição de cuidados sociais proposta por Daly e Lewis (ibid.), no sentido de considerar a prestação de cuidados como uma forma de trabalho, que se desenvolve em determinadas condições e que tem determinados tipos de custos. Segundo, o princípio defendido por Lyon e Glucksmann, e também por 
Daly e Lewis, de que cuidar, assim como qualquer outra forma de trabalho, pode decorrer através de diferentes relações socioeconómicas ou em diferentes espaços socioeconómicos (família, estado, mercado e terceiro setor/setor privado não lucrativo), o que significa que podem existir diferentes "modos de provisão" (Glucksmann, 2005; Lyon e Glucksmann, 2008).

A divisão da provisão de cuidados entre os cuidadores familiares e os cuidadores não familiares foi captada através da análise das seguintes dimensões: tarefas de cuidar realizadas pelos cuidadores familiares e pelos cuidadores não familiares; tempo dedicado à provisão de cuidados por parte dos cuidadores familiares (no seu conjunto) e por parte dos cuidadores não familiares (também no seu conjunto); setores de provisão aos quais os cuidadores não familiares pertencem; e significados atribuídos pelos cuidadores familiares à intervenção dos cuidadores não familiares.

Por seu lado, cinco categorias de cuidados emergiram da análise dos dados: cuidados no domínio das atividades da vida diária (AVD), como por exemplo dar banho, vestir e despir, fazer a higiene pessoal, dar a comida e a bebida, ajudar a andar, e ajudar a levantar e a sentar; ${ }^{4}$ cuidados no domínio das atividades instrumentais da vida diária (AIVD), tais como transportar, fazer as compras, fazer a limpeza doméstica, comprar os medicamentos e controlar a toma da medicação, e tratar de assuntos burocráticos; 5 apoio socioemocional, incluindo ouvir, proporcionar atividades recreativas, socializar, e estimular as capacidades cognitivas; coordenação, que implica controlar a assiduidade e a pontualidade dos cuidadores, controlar a qualidade dos serviços prestados e planear alterações nas soluções de prestação de cuidados; e cuidados holísticos, que incluem a provisão de cuidados nos domínios das AVD e das AIVD, a provisão de apoio socioemocional e a provisão de níveis mínimos de coordenação.

Em todas as formas de divisão dos cuidados, os cuidadores familiares e os cuidadores não familiares estão inseridos numa destas categorias de cuidados. A inserção numa dada categoria significa que os respetivos cuidadores prestam sobretudo, mas não exclusivamente, os cuidados que dela fazem parte (por exempo, a inserção na categoria atividades da vida diária significa que o cuidador presta cuidados sobretudo no domínio destas atividades, embora também possa prestar, residualmente, cuidados relacionados com o apoio socioemocional). Para além disto, a inserção numa destas categorias significa que os cuidadores prestam a maior parte, mas não a totalidade, dos cuidados incluídos nessa mesma categoria (por exempo, a inserção na categoria atividades da vida diária significa que o cuidador presta cuidados sobretudo no domínio destas atividades, mas não necessariamente todo o leque de possíveis cuidados relacionados com estas mesmas atividades).

No tocante ao tempo dedicado à provisão dos cuidados por parte dos cuidadores familiares (no seu conjunto) e dos cuidadores não familiares (também no seu conjunto), decidiu-se quantificar o número total de horas semanais que cada um

A lista completa de atividades da vida diária encontra-se em Katz e colegas (1963).

A lista completa de atividades instrumentais da vida diária encontra-se em Lawton e Brody (1969). 
destes grupos de cuidadores aloca à realização das tarefas de cuidar. Criaram-se três categorias temporais: número reduzido de horas (até 20 horas por semana); número elevado de horas (entre 20 e 40 horas por semana); e número muito elevado de horas (mais de 40 horas por semana). Esta forma de categorização baseou-se num horário de trabalho semanal de 40 horas, que é o que predomina em Portugal. ${ }^{6}$

Convém acrescentar que na análise da divisão dos cuidados consideram-se os perfis sociodemográficos dos cuidadores familiares, dos cuidadores não familiares e das próprias pessoas idosas.

Por último, a análise também levou em consideração os contextos sob os quais a divisão de cuidados se concretiza, não só os contextos micro (por exempo, recursos financeiros existentes na família), mas também os contextos macro (por exemplo, valores e normas sociais no que respeita aos cuidados familiares; infraestrutura de serviços sociais e seus modos de funcionamento, etc.).

Nesta ordem de ideias, o modelo concetual aqui proposto tem diversas vantagens em relação às concetualizações dicotómicas anteriormente revistas. Em primeiro lugar, permite incluir cuidadores pertencentes a diferentes setores de provisão (família, estado, mercado formal, mercado informal, e terceiro setor/setor privado não lucrativo), e explorar as possíveis interconexões existentes entre estes. Em segundo lugar, identifica rigorosamente as tarefas de cuidar realizadas pelas diferentes categorias de cuidadores e o tempo que cada uma destas consome na prestação de cuidados. Em terceiro lugar, toma em consideração os significados que os cuidadores intervenientes atribuem às respetivas formas de divisão dos cuidados. Por último, também presta atenção aos contextos nos quais a divisão dos cuidados se realiza.

\section{Estratégia de investigação e instrumentos de recolha de dados}

O estudo no qual este artigo se baseia seguiu uma estratégia de investigação qualitativa, mais concretamente uma abordagem narrativa/retrospetiva, de forma a captarem-se as trajetórias de cuidar (trajetórias realizadas pelos familiares inquiridos enquanto cuidadores). No âmbito desta abordagem metodológica, foram realizadas entrevistas semiestruturadas de pendor retrospetivo. A população alvo da qual foi retirada a amostra foi delimitada da seguinte forma: pessoas que cuidavam (ou tinham cuidado ao longo do último ano) de um familiar idoso em linha ascendente, e que residiam na área metropolitana de Lisboa. O familiar idoso teria que ter 65 ou mais anos e necessitar da ajuda de terceiros para a realização de atividades quotidianas indispensáveis para o seu bem-estar (AVD e/ou AIVD).

No total, foram entrevistados 54 indivíduos, contudo os resultados apresentados neste artigo não dizem respeito à totalidade destas entrevistas, visto que algumas dão conta de situações em que os cuidados recebidos pelas pessoas idosas

6 A quantificação do tempo dedicado aos cuidados pelos cuidadores familiares e pelos cuidadores não familiares permite-nos saber quem é que, de facto, está mais presente no "campo do cuidar", embora se reconheça que um mesmo número de horas semanais alocado aos cuidados possa ter diferentes significados para diferentes cuidadores. 
Quadro 1 Caracterização da amostra, segundo a relação de parentesco com a pessoa idosa, a condição perante o trabalho (empregado / não empregado) e a idade $\left(^{*}\right)$

\begin{tabular}{|c|c|c|c|c|c|}
\hline & \multicolumn{3}{|c|}{ Idade } & \multirow{2}{*}{ Total } \\
\hline & & $\leq 35$ & $36-55$ & $\geq 55$ & \\
\hline \multirow{2}{*}{ Filha } & Empregada & - & 18 & 2 & 20 \\
\hline & Não empregada & 1 & - & 4 & 5 \\
\hline \multirow{2}{*}{ Filho } & Empregado & 2 & 2 & 1 & 5 \\
\hline & Não empregado & - & - & 2 & 2 \\
\hline \multirow{2}{*}{ Nora } & Empregada & 2 & - & - & 2 \\
\hline & Não empregada & - & - & 1 & 1 \\
\hline \multirow{2}{*}{ Neta } & Empregada & 2 & 1 & - & 3 \\
\hline & Não empregada & - & - & - & - \\
\hline \multirow{2}{*}{ Sobrinha } & Empregada & - & 1 & 1 & 2 \\
\hline & Não empregada & - & - & - & - \\
\hline \multirow{2}{*}{ Mulher do neto } & Empregada & - & 1 & - & 1 \\
\hline & Não empregada & - & - & - & - \\
\hline \multicolumn{2}{|l|}{ Total } & 7 & 23 & 11 & 41 \\
\hline
\end{tabular}

$\left(^{*}\right)$ Estas características existiam no momento da realização das entrevistas; nos casos em que os inquiridos já não se encontravam a cuidar aquando da realização das entrevistas, a informação refere-se à última experiência de prestação de cuidados.

são prestados exclusivamente por familiares. ${ }^{7}$ Assim, a amostra usada neste artigo é constituída por 41 cuidadores familiares que integram soluções de prestação de cuidados que sempre foram mistas (combinação de cuidados familiares com cuidados não familiares), ou que deixaram de ser exclusivamente familiares e se tornaram mistas. ${ }^{8}$ A larga maioria destes cuidadores são filhas das pessoas idosas, apesar de haver também alguns filhos, noras, netas, sobrinhas e a mulher de um neto. Mais de metade têm entre 36 e 55 anos. Acima e abaixo desta faixa etária, a maior parte têm mais do que 55 anos e os restantes têm menos do que 36 . São cuidadores que têm empregos a tempo inteiro, com a exceção de oito que estão desempregados ou já reformados (quadro 1). Relativamente ao nível de escolaridade, existe uma grande heterogeneidade, embora a maior parte dos cuidadores tenham 12 ou mais anos de escolaridade. Os que estão empregados exercem diversas profissões, as quais tendem a refletir os níveis de escolaridade. Em termos de posições de classe, verifica-se que os inquiridos se inserem, maioritariamente, em distintas frações das classes médias urbanas da região de Lisboa: a maior parte insere-se

7 Existem três razões principais que explicam porque é que algumas soluções de prestação de cuidados são constituídas apenas por familiares: os cuidadores familiares ainda não sentiram necessidade de recorrer à ajuda de cuidadores não familiares; as pessoas idosas recusam-se a receber cuidados de não familiares; e os cuidadores familiares ainda não encontraram cuidadores não familiares apropriados.

8 De entre os 41 cuidadores entrevistados, a maioria (26) tem participado em soluções de prestação de cuidados que sempre foram mistas. 
numa fração caracterizada pela posse de elevados volumes de capitais económicos e escolares (profissões intelectuais e científicas), a seguir aparece uma fração que se posiciona no polo oposto (empregados executantes), e por último duas frações que se situam entre estas duas (profissões técnicas e de enquadramento intermédio, e independentes e pequenos patrões do secundário e terciário). São muito poucos os inquiridos que pertencem à classe dos empresários e dirigentes e às classes dos empregados não qualificados do terciário e do operariado industrial.

Visto tratar-se de uma investigação qualitativa, de natureza exploratória, a seleção dos entrevistados foi guiada pelo princípio da diversidade, pois houve a preocupação de constituir uma amostra heterogénea em termos de género, idade, relação de parentesco com a pessoa idosa, condição perante o trabalho, estado civil, condição perante a parentalidade, e nível de rendimentos e de escolaridade. Também se procurou incluir cuidadores familiares de pessoas idosas com diversos graus de incapacidade. ${ }^{9}$

Foram usadas diversas técnicas de amostragem, nomeadamente a amostragem por conveniência, por "bola de neve" e a amostragem intencional. Esta última técnica de amostragem serviu para corrigir os desequilíbrios resultantes da utilização das primeiras duas técnicas, e para garantir a diversidade atrás mencionada. A seleção de alguns dos entrevistados foi realizada através da colaboração da Santa Casa da Misericórdia de Lisboa. ${ }^{10}$ Apenas uma minoria de familiares selecionados não se mostraram disponíveis para serem entrevistados. Nos casos em que isto aconteceu, os familiares selecionados indicaram outros membros da família com disponibilidade para colaborar na investigação.

Todas as entrevistas foram gravadas em registo áudio, e todos os registos foram transcritos integralmente. As transcrições das entrevistas foram analisadas de acordo com os princípios e os procedimentos da framework analysis. Esta abordagem analítica encontra-se descrita em Ritchie e Lewis (2003), entre outros.

\section{Resultados}

Formas de divisão dos cuidados: vantagens e desvantagens

Nesta secção dá-se conta das formas de divisão dos cuidados que foram identificadas, bem como das vantagens e desvantagens que lhes são atribuídas pelos cuidadores familiares entrevistados. Identificaram-se cinco formas de divisão dos cuidados: cuidados familiares tradicionais "modificados"; cuidados familiares emocionais

9 Na aferição das incapacidades das pessoas idosas não se usou nenhuma escala de medição do nível de dependência, tendo-se, alternativamente, optado por uma simples identificação dos cuidados de que, na perspetiva dos cuidadores entrevistados, as pessoas idosas necessitavam (cuidados nos domínios das AVD, AIVD, etc.).

10 Tendo em conta que apenas alguns dos entrevistados foram selecionados através da colaboração desta instituição (12 entrevistados), e que esta seleção respeitou o princípio da diversidade / heterogeneidade, julga-se que este conjunto de entrevistados não introduz nenhum tipo de enviesamento. 
complementados; cuidados familiares instrumentais complementados; cuidados mercantis; e cuidados mercantis "familiarizados".

Na primeira forma de divisão dos cuidados (cuidados familiares tradicionais "modificados"), as pessoas idosas necessitam de cuidados nos domínios das AIVD e das AVD, embora no respeitante às AVD a maioria precise de ajuda sobretudo ao nível do banho e da mobilidade física. Adicionando as necessidades de ordem emocional (reconhecidas pelos entrevistados), isto quer dizer que estas pessoas idosas necessitam de cuidados holísticos (embora umas mais do que outras), cuidados estes que exigem o dispêndio de uma quantidade significativa de tempo e de energia. Estamo-nos a referir a pessoas idosas que, excetuando dois casos, são viúvas e vivem com os seus cuidadores familiares. Por seu lado, os cuidadores familiares (dez filhas, dois filhos, duas netas e duas noras) têm empregos a tempo inteiro, excetuando alguns que estão desempregados ou reformados (três familiares).

Portanto, temos de um lado as pessoas idosas que precisam de cuidados holísticos, que requerem o dispêndio de bastante tempo e energia, e do outro lado familiares que têm limitações em termos de tempo disponível para os prestar devido às suas ocupações profissionais a tempo inteiro, e ainda uma minoria de familiares que têm tempo disponível, pois não estão inseridos no mercado e trabalho. Porém, todos os familiares inseridos nesta forma de divisão de cuidados asseguram a prestação da maior parte dos cuidados holísticos, de segunda-feira a domingo, alocando-lhes um número elevado de horas por semana. Importa acrescentar que estes cuidadores familiares não possuem recursos financeiros que lhes permitam delegar a prestação de cuidados no mercado (formal e informal).

Os cuidadores não familiares intervêm durante curtos períodos de tempo por dia. Nos casos dos trabalhadores do apoio domiciliário (terceiro setor), os cuidados diários (de segunda a sexta-feira na maior parte dos casos), centrados na higiene e na entrega de refeições, demoram cerca de 30 minutos por dia, ou seja, menos de três horas por semana. Nos casos dos trabalhadores de um centro de dia (terceiro setor), os cuidados, sobretudo apoio socioemocional, ${ }^{11}$ também acabam por durar pouco tempo por dia, visto que algumas pessoas idosas frequentam o centro durante metade do dia, enquanto outras saem e entram nele diversas vezes durante o dia. ${ }^{12}$

Nesta forma de divisão dos cuidados, os cuidadores familiares possuem características idênticas às dos cuidadores familiares "tradicionais" ou "clássicos", que segundo Ungerson (2005) prestam cuidados holísticos durante bastantes horas por semana (sem apoios fora da família), ao que se junta a coabitação com a pessoa idosa. Estes cuidadores familiares distanciam-se, contudo, dos "tradicionais", na medida em que a maioria, inclusivamente as mulheres, têm um emprego a

11 Em Portugal, a grande maioria dos centros de dia prestam essencialmente apoio socioemocional e não aceitam pessoas idosas que necessitam de ajuda no banho ou no comer e beber (São José e Wall, 2006).

12 Nos casos em que os cuidadores familiares não estão no mercado de trabalho, a intervenção dos cuidadores não familiares justifica-se pela incapacidade dos primeiros em prestar os cuidados mais "pesados" (higiene corporal) devido a problemas de saúde, ou, na perspetiva dos entrevistados, pela rejeição pelas pessoas idosas da possibilidade de receberem cuidados de higiene corporal da parte dos cuidadores familiares. 
tempo inteiro e contam com a ajuda, embora "mínima", de cuidadores não familiares. Relativamente a este último ponto, no discurso destes cuidadores familiares ressalta a ideia de que apenas recebem "alguma ajuda". Isto remete para o significado que atribuem a esta forma particular de divisão dos cuidados. Por exemplo, os cuidadores que trabalham a tempo inteiro referem que recebem ajuda apenas em certos períodos ao longo do dia:

- Porque é que recorreu aos serviços de apoio domiciliário?

- Porque nós [a filha entrevistada e a sua irmã] temos que trabalhar. Nós precisamos de alguém para nos ajudar, para nos ajudar a fazer-lhe a higiene que nós não conseguimos fazer de manhã, porque temos que estar no trabalho muito cedo. [E48] ${ }^{13}$

Os entrevistados que representam esta forma de divisão dos cuidados reconhecem que ter alguém para prestar os cuidados que eles não podem assegurar, embora por diversas razões, é um aspeto positivo a relevar. Porém, todos reportam, explícita ou implicitamente, que o forte envolvimento nos cuidados lhes deixa pouco tempo para os cônjuges e para os filhos (nos casos em que estes últimos existem). Para além disto, nalguns casos as pessoas idosas já necessitam de apoio permanente, mas como o apoio domiciliário intervém diariamente durante curtos períodos de tempo (casos em que os centros de dia não dão resposta), acabam por ficar entregues a si próprias durante várias horas, o que deixa os entrevistados bastante insatisfeitos e receosos pelo que lhes possa acontecer.

Na segunda forma de divisão dos cuidados (cuidados familiares emocionais complementados), encontramos pessoas idosas que apenas necessitam de apoio na realização de algumas AIVD e também de algum apoio emocional. Todas vivem com os seus cuidadores familiares.

Os cuidadores familiares (quatro filhas, duas sobrinhas, uma neta e a mulher de um neto) têm empregos a tempo inteiro, todos eles com remunerações acima da média, e prestam sobretudo cuidados socioemocionais. A prestação destes cuidados acaba por consumir um elevado número de horas por semana, não porque as pessoas idosas tenham uma forte necessidade destes cuidados, mas sim porque, na ótica destes familiares, a coabitação com estas últimas promove/facilita uma alocação substancial de tempo a estes mesmos cuidados.

O papel dos cuidadores não familiares restringe-se à prestação de cuidados no domínio das AIVD durante um número reduzido de horas por semana. São empregadas domésticas, operando no mercado informal, algumas delas imigrantes. Apesar de algumas destas empregadas trabalharem em casa dos entrevistados a tempo inteiro, a fração de tempo despendida no tratamento da roupa das pessoas idosas e na limpeza dos seus quartos é menor do que 20 horas por semana.

Esta forma de divisão dos cuidados é do agrado dos cuidadores familiares, visto que não têm dificuldades em conciliar a provisão de apoio socioemocional com outros domínios das suas vidas (o apoio socioemocional é prestado sobretudo

13 "E48" quer dizer entrevista n.․ 48. 
no período pós-laboral). Eis a forma como uma das filhas define o seu papel de cuidadora:

[...] o que eu faço é falar com ela, é basicamente conversa [...] a roupa e a limpeza da casa é com as empregadas domésticas. [E38]

Todos os cuidadores familiares que representam esta forma de divisão dos cuidados se concebem como "cuidadores emocionais", concebendo o trabalho das empregadas domésticas como um "complemento" de natureza instrumental.

Todavia, alguns dos cuidadores entrevistados explicitam que residir com as pessoas idosas implica uma diminuição da sua privacidade, o que leva, não raras vezes, a tensões entre ambas as partes.

Na terceira forma de divisão dos cuidados (cuidados familiares instrumentais complementados) as pessoas idosas têm necessidades nos domínios das AVD (sobretudo ao nível da higiene corporal e da mobilidade física) e das AIVD. São viúvas (excetuando uma cujo cônjuge também exibe algumas incapacidades) e não residem com os respetivos cuidadores familiares.

Por sua vez, os cuidadores familiares (três filhos e uma filha) têm empregos a tempo inteiro e residem não muito longe da casa das pessoas idosas. Metade destes cuidadores auferem salários relativamente baixos, ao passo que os restantes auferem salários entre os 750 e os 1000 euros por mês. No respeitante à prestação de cuidados, estes familiares intervêm sobretudo ao nível das AIVD (transporte, compras de supermercado, compras de medicamentos, tarefas burocráticas, etc.), o que lhes consome poucas horas por semana. Eis o testemunho de um dos filhos:

Eu trato das coisas práticas, compras e papelada, esse tipo de coisas. A higiene é assegurada pelas raparigas do apoio domiciliário. [E49]

Os cuidados no domínio das AVD são prestados pelo serviço de apoio domiciliário de uma instituição particular de solidariedade social. As trabalhadoras deste serviço consomem, em cada caso, cerca de 30 minutos por dia na prestação dos cuidados. São as pessoas idosas que contactam diretamente com o serviço de apoio domiciliário para tratar dos pagamentos e de outros assuntos de natureza prática.

Nestes casos, os cuidadores familiares, apesar de serem sobretudo "cuidadores instrumentais", concebem-se como os principais responsáveis pelo bem-estar das pessoas idosas, estando sempre disponíveis para qualquer eventualidade, e também olham para o trabalho dos cuidadores não familiares como um "complemento", embora de grande importância.

Estes cuidadores familiares enfatizam a boa articulação entre os cuidados e outras tarefas que fazem parte de diferentes domínios das suas vidas. Os homens cuidadores dão ainda importância ao facto de haver alguém que assegura a realização da higiene corporal das pessoas idosas. É de realçar que nenhum dos cuidadores que integram esta forma de divisão dos cuidados lhe atribui desvantagens. 
No que respeita à quarta forma de divisão dos cuidados (cuidados mercantis), as pessoas idosas apresentam necessidades de cuidados superiores às daquelas que estão inseridas nas anteriores formas de divisão dos cuidados. Muitas destas pessoas idosas estão acamadas, enquanto as restantes não estão acamadas mas têm grandes dificuldades ao nível da mobilidade física, e necessitam de cuidados ao nível da toma dos medicamentos, das refeições e da higiene corporal. Portanto, nestes casos os cuidados necessários requerem o dispêndio de um elevado número de horas por semana. Estas pessoas idosas são viúvas (exceto uma cujo cônjuge também precisa de cuidados) e não residem com os respetivos cuidadores familiares.

Os cuidadores familiares (cinco filhas) têm uma ocupação profissional a tempo inteiro, e auferem salários claramente acima da média. É precisamente o elevado volume de recursos financeiros que lhes possibilita a total delegação dos cuidados no domínio das AVD. Estes familiares assumem, assim, um papel essencialmente de coordenação ou supervisão dos cuidados prestados por terceiros. Acabam por consumir bastantes horas por semana nestas tarefas, visto que são eles que contactam com os cuidadores não familiares e que monitorizam a forma como os cuidados são prestados (controlo da pontualidade, assiduidade, qualidade do serviço, etc.). Isto implica deslocações diárias às casas das pessoas idosas. $\mathrm{O}$ seguinte depoimento ajuda a perceber o significado que é atribuído a esta forma particular de divisão de cuidados:

\begin{abstract}
A higiene, a alimentação, a limpeza, etc., isso está tudo delegado. Eu com isso não me preocupo. Mas isso não quer dizer que eu não tenha trabalho. Eu todos os dias passo em casa dos meus pais para saber se está tudo bem, se foram bem tratados, se comeram, etc. Para além disso, quando há qualquer coisa de novo (fora do habitual) sou eu que trato de tudo, sou eu que providencio para que não lhes falte nada. [E51].
\end{abstract}

Num dos casos os cuidadores não familiares são trabalhadoras de uma empresa privada de prestação de cuidados ao domicílio, cobrindo, em regime de turnos, 24 horas por dia durante sete dias por semana. Nos restantes casos, são trabalhadoras independentes, operando no mercado informal, algumas delas imigrantes, prestando cuidados de segunda-feira a sábado durante cerca de 12 horas por dia.

Esta forma de divisão dos cuidados assenta numa relação puramente mercantil entre os cuidadores familiares e os cuidadores não familiares, ou seja, assenta numa relação de "compra e venda" de serviços. Por outras palavras, os cuidadores não familiares são tratados como meros "prestadores de serviços", estando a relação entre estes e os cuidadores familiares pautada por diversos formalismos.

Estes familiares salientam a boa articulação entre o domínio do cuidar e outros domínios das suas vidas (por exemplo, trabalho profissional e lazer), que é proporcionada pela forte delegação da prestação de cuidados no mercado. No entanto, referem que não possuem total autonomia para fazerem o que desejam, pois têm que planear muitas das suas atividades com antecedência, como por exemplo as atividades de lazer. 
Na última forma de divisão dos cuidados (cuidados mercantis "familiarizados"), as pessoas idosas estão acamadas, são viúvas e residem com os seus cuidadores familiares. São pessoas que requerem cuidados permanentes, praticamente durante 24 horas por dia durante sete dias por semana.

Trata-se de dois casos em que ambos os cuidadores familiares são filhos: uma filha, solteira, com um emprego a tempo inteiro, trabalhando, por vezes, durante a noite (é profissional de saúde), e um filho, também solteiro e já reformado. Tanto os filhos como as pessoas idosas possuem abundantes recursos financeiros. Ambos os filhos prestam cuidados holísticos durante um elevado número de horas por semana. A filha, mesmo trabalhando fora de casa, também dedica muitas horas aos cuidados, pois durante a noite é muito solicitada pela mãe.

Os cuidadores não familiares também prestam cuidados holísticos durante um número ainda mais elevado de horas por semana. São mulheres que trabalham de uma forma independente, operando no mercado informal. É de salientar que estas mulheres residem na mesma casa onde residem as pessoas idosas e os cuidadores familiares. No caso do filho, este apoio não familiar justifica-se pelo facto de a pessoa idosa (mulher) não desejar ser cuidada por ele.

Assim, tal como na anterior forma de divisão dos cuidados, existe uma forte delegação dos cuidados no mercado, aliás uma delegação ainda mais forte. Porém, curiosamente a relação entre os cuidadores familiares e os cuidadores não familiares vai para além de uma relação de pura "compra e venda" de serviços. As empregadas domésticas não só desempenham um papel muito idêntico ao dos cuidadores familiares (prestam cuidados holísticos e despendem muito tempo nos cuidados), como também residem com as pessoas idosas. Para além disto, elas são tratadas "como família" pelos cuidadores familiares e estes esperam que, na prática, ajam como cuidadoras familiares, isto é, como cuidadoras carinhosas. Nestes casos, os cuidados não familiares contêm elementos práticos e simbólicos típicos dos cuidados familiares. Para isto contribui o relacionamento prolongado das empregadas domésticas com os cuidadores familiares e respetivas pessoas idosas (mais de dois anos). Vejamos como é que o filho "olha" para a empregada, o que dá conta do significado que ele atribui a esta forma particular de divisão dos cuidados:

- Ela é como se fosse da família, tem estado aqui já lá vão três anos, ela praticamente já pertence à família.

- Está satisfeito com esta solução?

- Sim, muito satisfeito, ela trata da minha mãe como se fosse a mãe dela, e eu gosto muito disso. Para mim é muito importante que a minha mãe fique aqui comigo, em casa, tendo todos os cuidados que precisa. [E9]

Como vantagens desta forma de divisão dos cuidados, os cuidadores familiares apontam o facto de terem alguém disponível para prestar os cuidados de que as pessoas idosas necessitam durante 24 horas por dia. Este apoio é vital para estes dois cuidadores, pois os idosos necessitam de cuidados permanentes: a filha consegue conciliar os cuidados com a sua atividade profissional, e o filho pode delegar a prestação dos cuidados de higiene corporal, cuidados estes que, segundo a sua 
perspetiva, a mãe não deseja receber da sua parte. Poder-se prestar os cuidados num ambiente familiar é outra das vantagens referidas por ambos os cuidadores.

Curiosamente, apesar do intenso apoio que recebem, estes cuidadores familiares também identificam alguns aspetos desvantajosos subjacentes a esta forma de divisão dos cuidados, nomeadamente a falta de privacidade (que deriva da coabitação com as pessoas idosas e com as empregadas domésticas), a falta de tempo para eles próprios (devido à alocação de bastantes horas aos cuidados), e o número insuficiente de horas de sono (pois têm que se levantar durante a noite para prestar cuidados).

\section{A divisão dos cuidados no futuro}

Para além das vantagens e desvantagens associadas a cada forma de divisão dos cuidados, interessa também saber, a partir das perspetivas dos entrevistados, como é que será, de um ponto de vista realístico, a futura divisão dos cuidados quando as pessoas idosas exibirem mais incapacidades (divisão esperada), assim como a divisão de cuidados que gostariam idealmente de ter quando esta situação ocorrer (divisão desejada/idealizada).

Alguns entrevistados esperam, de uma forma realística, recorrer aos serviços de um lar pertencente ao estado ou ao terceiro setor (alguns cuidadores familiares inseridos nos "cuidados familiares tradicionais modificados" e nos "cuidados familiares instrumentais complementados"). Outros só veem como alternativa recorrer a um hospital público, pois os rendimentos familiares são de tal maneira escassos que não consideram viável o recurso a um lar, mesmo sendo público (alguns cuidadores inseridos nos "cuidados familiares tradicionais modificados"). Por sua vez, os cuidadores que integram os "cuidados familiares emocionais complementados" esperam comprar serviços de apoio domiciliário a tempo inteiro ou mesmo durante 24 horas por dia, pois existem suficientes recursos financeiros nas respetivas famílias, ao passo que alguns dos que representam os "cuidados familiares instrumentais complementados" tencionam comprar serviços de apoio domiciliário a tempo inteiro, pois não dispõem de suficientes recursos financeiros para comprar serviços 24 horas por dia. Há ainda cuidadores que já têm apoio domiciliário durante cerca de 12 horas por dia e que esperam alargar estes serviços para um período de 24 horas quando as pessoas idosas ficarem bastante incapacitadas (alguns cuidadores inseridos nos "cuidados mercantis"). Por último, existem cuidadores familiares que esperam manter a atual divisão dos cuidados, visto que já contam com apoio domiciliário durante 24 horas por dia (alguns cuidadores inseridos nos "cuidados mercantis" e todos os cuidadores que representam os "cuidados mercantis familiarizados"). Existem, assim, diferentes planos em relação à divisão esperada dos cuidados no futuro, que se prendem, em grande parte, com diferentes disponibilidades de recursos financeiros.

No que concerne à divisão desejada/idealizada dos cuidados, é interessante constatar, em primeiro lugar, que nalguns casos a divisão que muito provavelmente será implementada no futuro coincide, precisamente, com a divisão desejada (todos os cuidadores inseridos nos "cuidados familiares emocionais complementados", "cuidados mercantis" e "cuidados mercantis familiarizados", e alguns 
inseridos nos "cuidados familiares instrumentais complementados"). Contudo, para os restantes a divisão esperada dos cuidados não corresponde àquela que gostariam de implementar. Esta descoincidência tem a ver com a escassez de recursos financeiros disponíveis nas famílias, que no contexto da atual infraestrutura de serviços sociais para a população idosa pertencente ao setor público ou ao terceiro setor (os centros de dia operam cerca de oito horas por dia, mas não recebem pessoas idosas com níveis elevados de incapacidade, e os serviços de apoio domiciliário têm intervenções diárias que não totalizam mais do que 30 minutos por dia), é impeditiva do acesso a serviços sociais de longa duração (oito ou mais horas por dia). Em segundo lugar, constata-se que uma divisão dos cuidados em que os cuidadores não familiares prestam apoio domiciliário a tempo inteiro ou 24 horas por dia é, para todos os cuidadores familiares entrevistados, a divisão desejada ou a divisão ideal. Este resultado é consistente com o facto de também todos os entrevistados afirmarem, embora uns de uma forma mais veemente do que outros, que o recurso a um lar só será equacionado no caso de não haver outras soluções alternativas. Diversos estudos quantitativos baseados em amostras representativas da população portuguesa evidenciam que a grande maioria dos portugueses prefere uma solução de cuidados assente na família e na coabitação com a pessoa idosa (na casa desta ou na casa de um dos seus filhos), e rejeitam qualquer solução que implique a institucionalização desta última (ver p. ex.: Eurobarometer, 2007).

Olhando para os resultados referentes às vantagens e desvantagens atribuídas a cada forma de divisão dos cuidados, bem como para os resultados referentes à futura divisão dos cuidados (divisão esperada e divisão desejada), sobressaem várias ideias importantes. Em primeiro lugar, as situações em que as pessoas idosas com necessidades de apoio permanente ficam sozinhas em casa durante várias horas por dia poderiam ser evitadas caso recebessem apoio domiciliário com intervenções diárias mais duradouras, tal como desejariam os cuidadores familiares. Em segundo lugar, alguns cuidadores familiares já beneficiam de apoio domiciliário com intervenções diárias de longa duração (oito horas ou mais) e pretendem mantê-lo, pois é um apoio que tem a vantagem de lhes permitir assegurar uma boa articulação entre a prestação de cuidados e outros domínios das suas vidas. Por seu lado, outros cuidadores ainda não beneficiam deste apoio mas esperam, realisticamente, recebê-lo no futuro, existindo ainda outros que gostariam de receber futuramente este apoio, mas consideram que não será viável por falta de recursos financeiros. Isto permite concluir que uma combinação de cuidados familiares com apoio domiciliário flexível em termos de duração das suas intervenções diárias é, na perspetiva dos cuidadores familiares entrevistados, a forma ideal de divisão dos cuidados entre os cuidadores familiares e os cuidadores não familiares. O apoio domiciliário de longa duração é particularmente importante quando os idosos começam a precisar de cuidados permanentes/contínuos. 


\section{Discussão dos resultados e principais conclusões}

Os resultados atrás descritos permitem um acesso "próximo" à realidade dos cuidados sociais na comunidade. De entre os vários pontos que se poderiam discutir, destacamos aqueles que nos parecem ser mais relevantes do ponto de vista sociológico, bem como dos pontos de vista das práticas profissionais e das políticas sociais.

Em primeiro lugar, estes resultados evidenciam uma pluralidade de formas de divisão dos cuidados entre cuidadores familiares e cuidadores não familiares, as quais assentam em diferentes interconexões. Estas interconexões, de complexidade variável, ter-nos-iam muito provavelmente escapado se tivéssemos utilizado as concetualizações dicotómicas discutidas na introdução. Vejamos dois exemplos que sustentam esta ideia. Ficou demonstrado que um forte envolvimento de cuidadores não familiares na prestação de cuidados (cuidados mercantis e cuidados mercantis "familiarizados") não implica, necessariamente, a (total) "substituição" de cuidadores familiares ou a "desfamiliarização" dos cuidados. No que toca à forma de divisão "cuidados mercantis", os cuidadores familiares não deixaram de ser cuidadores. É verdade que os cuidadores não familiares os substituem na prestação de cuidados no domínio das AVD, mas eles continuam a ser responsáveis pelo bem-estar das pessoas idosas e a dedicar bastantes horas por semana a tarefas de coordenação/supervisão. Isto quer dizer que estes cuidadores familiares continuam no "campo dos cuidados", embora não estejam na "linha da frente". Por conseguinte, parece-nos pouco defensável afirmar que esta forma de divisão dos cuidados se baseia na "substituição" em vez da "complementaridade". Por sua vez, na forma de divisão "cuidados mercantis familiarizados" os cuidadores não familiares foram cooptados para serem "como se fossem familiares" e, na ótica dos familiares entrevistados, agem como tal. Por isso, é muito difícil sustentar que existe "desfamiliarização". Portanto, conclui-se que o modelo concetual utilizado neste artigo provou ser profícuo na captação dos complexos entrelaçamentos, e nalguns casos também do hibridismo (particularmente visível nos cuidados mercantis "familiarizados"), que existe na divisão dos cuidados entre cuidadores familiares e cuidadores não familiares, aspetos estes que não têm sido evidenciados pela investigação precedente.

O conhecimento destas microdinâmicas, de onde sobressaem a diversidade e a complexidade, é, no nosso entender, fundamental, não só para a criação/afinação de instrumentos concetuais, mas também para o desenvolvimento de práticas profissionais e políticas sociais mais sustentadas em evidência empírica, logo mais eficazes e mais eficientes.

Em segundo lugar, a pluralidade de formas de divisão dos cuidados resulta, em grande parte, de diferentes combinações entre necessidades das pessoas idosas e recursos disponíveis nas famílias, sobretudo recursos financeiros, para responder a essas necessidades. Para além disto, vimos que a forma como os cuidados são divididos entre os cuidadores familiares e os cuidadores não familiares (quem faz o quê e durante quanto tempo?) também é condicionada pela coabitação (ou não) entre os cuidadores familiares e as pessoas idosas.

Relativamente à importância dos recursos financeiros, tivemos a oportunidade de constatar que as formas de divisão dos cuidados no presente são claramente 
diferenciadas do ponto de vista socioeconómico: encontrámos formas de divisão "ricas" (por exemplo, cuidados mercantis e cuidados mercantis "familiarizados") e formas de divisão "pobres" (por exemplo, cuidados familiares tradicionais "modificados"), em que nalguns casos os idosos já precisam de cuidados permanentes mas ficam sozinhos em casa durante bastantes horas por dia. Também vimos que muitos dos familiares entrevistados não veem outra alternativa senão recorrer a um lar da rede pública ou a um hospital público quando as pessoas idosas ficarem mais incapacitadas, ao passo que outros esperam desenvolver ou manter uma divisão de cuidados com uma forte participação de cuidadores não familiares que operam no mercado (formal ou informal). Porém, isto só acontece porque o setor público e o setor particular não lucrativo, setores financeiramente acessíveis à maioria dos portugueses, não oferecem serviços comunitários "amigos dos cuidadores familiares" (os centros de dia não dão resposta às situações de elevada dependência, e o apoio domiciliário não presta serviços com intervenções diárias de longa duração), fazendo com que as famílias com escassos recursos financeiros fiquem impedidas de recorrer a cuidados sociais que permitam manter na comunidade as pessoas idosas com níveis médios/elevados de incapacidade. Portanto, conclui-se que a infraestrutura de serviços sociais existente em Portugal e o seu modo de funcionamento permitem a reprodução das vantagens para uma minoria e não impedem a reprodução das desvantagens para uma maioria.

O papel desempenhado pela posição de classe (especialmente pelos capitais económicos) no acesso a cuidados sociais tem sido documentado por estudos realizados em diferentes países (ver, p. ex.: Arber e Ginn, 1992; Egger de Campo, 2007). Em Portugal, a investigação já realizada mostra que nos meios sociais mais desprovidos de recursos económicos a "sociedade-providência" não tem capacidade para compensar a deficiente intervenção do estado-providência (ver, p. ex.: Wall e outros, 2001; Gil, 2010). Os resultados apresentados e discutidos neste artigo vão ao encontro desta evidência empírica.

Relativamente ao papel da coabitação entre os cuidadores familiares e as pessoas idosas na forma como os cuidados são divididos, vimos que este é relevante no tipo de tarefas que os cuidadores familiares realizam e no número de horas que lhes alocam, o que vai ao encontro dos resultados de outras investigações (p. ex., Gil, 2010). Todavia, julgamos que é necessário compreender melhor o papel da coabitação em futuras investigações.

As formas de divisão dos cuidados são, como já sublinhámos, marcadas por desigualdades de classe social, onde os recursos financeiros detêm um papel determinante. Contudo, também constatámos que as formas de divisão dos cuidados são, de igual modo, muito marcadas pelo género, pois a grande maioria dos cuidadores familiares e a totalidade dos cuidadores não familiares são mulheres. Outros estudos realizados sobre a realidade portuguesa também evidenciam o papel preponderante da mulher nos cuidados às pessoas idosas (Quaresma, 1996; São José e Wall, 2006). Isto é o reflexo, em grande parte, do sistema cultural português, que continua a esperar que a mulher assuma a principal responsabilidade pela prestação de cuidados, e também das dinâmicas dos setores não familiares de provisão de cuidados sociais, que continuam a "apostar" nas baixas qualificações e nos 
baixos salários, sendo por isso pouco "apelativos" para os homens. Tronto (1993) e Williams (2004) sugerem que a criação de uma "ética de cuidar", que valorizasse socialmente a atividade de cuidar - o que implicaria, entre outras medidas, retirar os cuidados familiares da invisibilidade social a que têm estado remetidos (Fernandes e outros, 2010) - , contribuiria para ultrapassar a ideia de que os cuidados são um assunto exclusivamente do foro da vida privada e um apanágio natural das mulheres, o que, por conseguinte, criaria uma maior igualdade de género no domínio dos cuidados sociais.

Assim, podemos concluir que a divisão dos cuidados sociais revelada neste artigo é claramente marcada por desigualdades sociais, nomeadamente por desigualdades de classe social e de género, as quais estão ancoradas em sistemas institucionais e culturais da sociedade portuguesa. Isto é particularmente relevante do ponto de vista das políticas sociais, visto que a intervenção estatal no sentido das propostas apresentadas neste artigo poderia atenuar significativamente estas desigualdades.

Em terceiro lugar, também ficou evidenciado que as preferências dos cuidadores familiares entrevistados no que respeita a cuidados não familiares apontam, inequivocamente, para um apoio domiciliário "amigo do cuidador familiar" (e certamente também amigo das pessoas idosas), isto é, apoio domiciliário que possa ir até oito ou mais horas por dia caso seja necessário. Existem outros estudos realizados em Portugal que apontam para a necessidade de reestruturação do serviço de apoio domiciliário precisamente neste sentido (p. ex.: Romão e Pereira, 2008; Gil, 2009). ${ }^{14}$

Conclui-se, assim, que estes cuidadores familiares veem o apoio familiar "amigo do cuidador familiar" como o aliado privilegiado na gestão dos cuidados sociais prestados a pessoas idosas. O acesso a apoio domiciliário "amigo do cuidador familiar" por parte da generalidade dos cuidadores familiares portugueses poderia ser garantido através de duas estratégias distintas (a hipótese de o estado assegurar a provisão direta de apoio domiciliário não parece ser verosímil): promover o alargamento da duração diária do apoio domiciliário provido pelo terceiro setor, ou desenvolver um sistema de prestações sociais (cash-for-care) que permitisse a compra de apoio domiciliário prestado pelo mercado (formal e informal).

Ambas as estratégias comportariam, inevitavelmente, um aumento dos gastos públicos, que não são contabilizados no âmbito deste artigo. Poderiam também criar alguns riscos para os próprios cuidadores familiares e para as pessoas idosas. Por exemplo, a primeira estratégia (alargar a duração diária do apoio domiciliário do terceiro setor) reforçaria a posição "monopolística" que este setor detém atualmente no domínio dos serviços sociais para a população idosa, o que, segundo

14 Não obstante, também tivemos a oportunidade de constatar que ter apoio domiciliário 24 horas por dia, numa situação em que as pessoas idosas com elevados níveis de incapacidade e os cuidadores não familiares residem com os cuidadores familiares, não garante ausência total de dificuldades para estes últimos. Este ponto merece ser explorado de uma forma mais aprofundada em futuras investigações. 
alguns autores (p. ex., Pavolini e Ranci, 2008), limitaria a margem de manobra para a escolha por parte das pessoas idosas e dos seus cuidadores familiares. Por seu lado, a segunda estratégia (desenvolver um sistema de prestações sociais vocacionadas para a compra de apoio domiciliário) poderia contribuir para a expansão do mercado informal (Ungerson, 2003), como tem acontecido na Itália e na Áustria (Rostgaard, 2011; Da Roit, 2007), e para a concomitante expansão do cuidar sem qualidade e sem proteção para as pessoas idosas e para os cuidadores (Marin e outros, 2009; Ungerson, 2003), a não ser que o estado criasse regulamentos no sentido de impedir que as prestações sociais fossem utilizadas para comprar serviços não declarados. O fomento de apoios financeiros para comprar cuidados poderia, ainda, reforçar as desigualdades de género, pois estes apoios, mesmo que pouco generosos, seriam um incentivo para as mulheres, tradicionais cuidadoras, permanecerem em casa dedicando-se às tarefas domésticas e aos cuidados (Ungerson, 2000).

Não obstante estes potenciais riscos, cada uma destas estratégias traria, certamente, diversas vantagens para os cuidadores familiares e para as pessoas idosas. O alargamento da duração diária do apoio domiciliário do terceiro setor poderia prevenir situações em que as pessoas idosas ficam entregues a si próprias durante longos períodos de tempo, facilitar a conciliação entre o papel de cuidador familiar e o papel de empregado a tempo inteiro (Pavolini e Ranci, 2008), e prevenir a institucionalização precoce das pessoas idosas e reduzir as hospitalizações (Gaugler e outros, 2005; Marin e outros, 2009). O desenvolvimento de prestações sociais para a compra de apoios domiciliários traria, por seu turno, as mesmas vantagens acabadas de enunciar, às quais se poderiam juntar uma maior margem de manobra para os cuidadores familiares e as pessoas idosas fazerem escolhas, dado que poderiam usar os apoios financeiros para pagar a familiares ou a amigos (caso fosse permitido) ou para pagar serviços prestados pelo mercado (Pavolini e Ranci, 2008), e um reconhecimento público do papel desempenhado pela família caso as prestações socais pudessem ser usadas para pagar a cuidadores familiares (Rostgaard, 2011; Huber e outros, 2009).

Considerando que em Portugal predomina o modelo de "duplo emprego" no que respeita à divisão conjugal do trabalho profissional (Aboim, 2010), o qual nãoé adequadamente apoiado por parte das políticas sociais nas situações em que existem pessoas idosas com necessidades de cuidados ("familiarismo implícito"), o desenvolvimento de apoio domiciliário "amigo do cuidador familiar" reforçaria o modelo de "duplo emprego", o que por sua vez contribuiria para o reforço da igualdade de género, quer no domínio do trabalho profissional, quer no domínio da prestação de cuidados.

\section{Referências bibliográficas}

Aboim, Sofia (2010), "Género, família e mudança em Portugal", em Karin Wall, Sofia Aboim e Vanessa Cunha (coords.), A Vida Familiar no Masculino. Negociando Velhas e Novas Masculinidades, Lisboa, Comissão para a Igualdade no Trabalho e no Emprego, pp. 39-66. 
Anttonen, Anneli, e Jorma Sipilä (1996), “European social care services: is it possible to identify models?", Journal of European Social Policy, 6 (2), pp. 87-100.

Arber, Sara, e Claudine Attias-Donfut (2000), The Myth of Generational Conflict. The Family and State in Ageing Societies, Londres e Nova Iorque, Routledge.

Arber, Sara, e Jay Ginn (1992), "Research note. Class and caring: a forgotten dimension", Sociology, 26 (4), pp. 619-634.

Bettio, Francesca, e Janneke Plantenga (2004), “Comparing care regimes in Europe”, Feminist Economics, 10 (1), pp. 85-113.

Chappell, Neena, e A. Blandford (1991), “Informal and formal care: exploring the complementarity”, Ageing \& Society, 11 (3), pp. 299-317.

Da Roit, Barbara (2007), "Changing intergenerational solidarities within families in a mediterranean welfare state: elderly care in Italy", Current Sociology, 55 (2), pp. 251-269.

Daly, Mary, e Jane Lewis (2000), “The concept of social care and the analysis of contemporary welfare states", British Journal of Sociology, 51 (2), pp. 281-299.

Egger de Campo, Marianne (2007), “Exit and voice: an investigation of care service users in Austria, Belgium, Italy and Northern Ireland", European Journal of Ageing, 4 (2), pp. 59-69.

Eurobarometer (2007), Health and Long-Term Care in the European Union. Report, Special Eurobarometer, 283/Wave 67.3, disponível em: http://ec.europa.eu/public_opinion/archives/ebs/ebs_283_en.pdf

Fernandes, Ana Alexandre, Ana Paula Gil, e I. Gomes (2010), “Fora de cena: invisibilidades sociais na última etapa da trajectória de vida", em António Dornelas, Luísa Oliveira, Luísa Veloso e Maria das Dores Guerreiro (orgs.), Portugal Invisível, Lisboa, Editora Mundos Sociais, pp. 173-198.

Gaugler, Joseph E., R. L. Kane, R. A. Kane, e R. Newcomer (2005), “Early community-based service utilization and its effects on institutionalization in dementia caregiving", The Gerontologist, 45 (2), pp. 177-185.

Geissler, Birgit, e B. Pfau-Effinger (2005), “Change in European care arrangements”, em Birgit Pfau-Effinger e Birgit Geissler (orgs.), Care and Social Integration in European Societies, Bristol, Policy Press, pp. 3-19.

Gil, Ana Paula (2009), Serviços de Apoio Domiciliário. Oferta e Custos no Mercado Privado, Lisboa, Instituto da Segurança Social.

Gil, Ana Paula (2010), Heróis do Quotidiano. Dinâmicas Familiares na Dependência, Lisboa, Fundação Calouste Gulbenkian/FCT.

Glucksmann, Miriam A. (2005), “Shifting boundaries and interconnections: extending the 'total social organisation of labour'”, The Sociological Review, vol. 53, n. ${ }^{\circ}$ esp., supl. s2, pp. 19-36.

Hubber, Manfered, R. Rodrigues, F. Hoffmann, K. Gasior, e B. Marin (2009), Facts and Figures on Long-Term Care. Europe and North America, Viena, European Centre.

Katz, Sidney, A. B. Ford, R. W. Moskowitz, B. A. Jackson, e M. W. Jaffee (1963), “Studies of illness in the aged: the index of ADL, a standardized measure of biological and psychological function", Journal of the American Medical Association, 185 (12), pp. 914-919.

Lawton, M. Powell, e Elaine M. Brody (1969), “Assessment of older people: self-maintaining and instrumental activities of daily living", The Gerontologist, 9 (3), pp. 179-186. 
Leitner, Sigrid (2003), "Varieties of familialism: the carin function of the family in comparative perspective", European Societies, 5 (4), pp. 353-375.

Litwin, Howard, e C. Attias-Donfut (2009), “The inter-relationship between formal and informal care: a study in France and Israel", Ageing \& Society, 29 (1), pp. 71-91.

Lyon, Dawn, e Miriam Glucksmann (2008), “Comparative configurations of care work across Europe", Sociology, 42 (1), pp. 101-118.

Marin, Bernd, K. Leichsenring, R. Rodrigues, e M. Huber (2009), Who Cares? Care Coordination and Cooperation to Enhance Quality in Elderly Care in the European Union, Viena, European Centre for Social Welfare Policy and Research, disponível em: http://www.euro.centre.org/data/1253632621_9637.pdf

Motel-Klingebiel, Andreas, C. Tesch-Roemer, e H.-J. Von Kondratowitz (2005), “Welfare states do not crowd out the family: evidence for mixed responsibility from comparative analyses", Ageing \& Society, 25 (6), pp. 863-882.

Pavolini, Emmanuele, e Costanzo Ranci (2008), "Restructuring the welfare state: reforms in long-term care in Western European countries", Journal of European Social Policy, 18 , pp. 246-259.

Quaresma, Maria de Lurdes (1996), Cuidados Familiares aos Idosos, Lisboa, DGAS.

Ritchie, Jane, e Jane Lewis (2003), Qualitative Research Practice. A Guide for Social Science Students and Researchers, Thousand Oaks, Sage Publications.

Romão, Ana, e A. Pereira (2008), “Cuidadores informais de idosos: conhecer os colaboradores da SCML", Revista Cidade Solidária, 19, disponível em: http://www.scml.pt/default.asp?site=revista\&sub=\&id=1\&mnu=1\&layout=\&page=6 (consultado em 21/6/2012).

Rostgaard, Tine (coord.) (2011), Livindhome. Living Independently at Home. Reforms in Home Care in 9 European Countries, Copenhaga, The Danish National Centre for Social Research, disponível em: http://www.sfi.dk/Files/Filer/SFI/LIVINDHOME/LIVINDHOME.pdf

São José, José (2009), Cuidar de Um Familiar Idoso Dependente. Trajectórias de Cuidar e Seus Significados, Lisboa, Instituto de Ciências Sociais da Universidade de Lisboa, tese de doutoramento.

São José, José, e Karin Wall (2006), “Trabalhar e cuidar de um idoso dependente: problemas e soluções", Cadernos Sociedade e Trabalho, VII, pp. 119-154.

Saraceno, Chiara, and Wolfgang Keck (2010), “Can we identify intergenerational policy regimes in Europe?", European Societies, 12 (5), pp. 675-696.

Tronto, Joan C. (1993), Moral Boundaries. A Political Argument for an Ethic of Care, Londres, Routledge.

Ungerson, Clare (2000), “Thinking about the production and consumption of long-term care in Britain: does gender still matter?", Journal of Social Policy, 29 (4), pp. 623-643.

Ungerson, Clare (2003), “Commodified care work in European labour markets”, European Societies, 5 (4), pp. 377-396.

Ungerson, Clare (2005), “Care, work and feeling”, The Sociological Review, 53, pp. 188-203, DOI: 10.1111/j.1467-954X.2005.00580.x

Wall, Karin, Sofia Aboim, Vanessa Cunha, e Pedro Vasconcelos (2001), “Families and informal support networks in Portugal: the reproduction of inequality", Journal of European Social Policy, 11 (3), pp. 213-233.

Williams, Fiona (2004), Rethinking Families, Londres, Calouste Gulbenkian Foundation. 
José de São José. Docente na Faculdade de Economia da Universidade do Algarve. E-mail: jsjose@ualg.pt

\section{Resumo/ abstract/ résumé/ resumen}

A divisão dos cuidados sociais prestados a pessoas idosas: complexidades, desigualdades e preferências

Este artigo, baseado numa investigação qualitativa, dá conta da divisão da provisão de cuidados sociais a pessoas idosas entre cuidadores familiares e cuidadores não familiares. A partir de um modelo concetual que evita as dicotomias usadas pela investigação já realizada sobre este tema, os dados recolhidos e analisados revelam complexidades e hibridismos na divisão dos cuidados, bem como desigualdades de classe social e de género. Para além disto, os cuidadores familiares entrevistados elegem a combinação de cuidados familiares com apoio domiciliário "amigo do cuidador familiar" (cujas intervenções possam ir até oito ou mais horas por dia) como a forma preferida/ideal de divisão dos cuidados. A relevância destes resultados, não só do ponto de vista sociológico, mas também dos pontos de vista das práticas profissionais e das políticas sociais, é discutida aprofundadamente.

Palavras-chave pessoas idosas, divisão dos cuidados, apoio domiciliário, políticas sociais.

The division of the social care provided to the elderly: complexities, inequalities and preferences

This article, which is based on qualitative research, talks about how the provision of social care to the elderly is divided up between family and non-family carers. Working from a conceptual model which avoids the dichotomies used in the research that has already been done on this topic, the data which the author has gathered and analysed reveal complexities and hybridisms in the division of care, as well as inequalities linked to social class and gender. In addition, the family carers who were interviewed chose the combination of family care with domiciliary support - the "family carer's friend" (whose interventions can involve eight or more hours a day) - as the preferred/ideal way of dividing care. The importance of these results is discussed in depth, not only from a sociological point of view, but also in terms of professional practices and social policies.

$\underline{\text { Keywords }}$ elderly persons, division of care, domiciliary support, social policies. 
La répartition des soins apportés aux personnes âgées: complexités, inégalités et préférences

Cet article, qui est basé sur une recherche qualitative, rend compte de la répartition des soins apportés aux personnes âgées entre les proches et les professionnels. À partir d'un modèle conceptuel qui évite les dichotomies utilisées par la recherche déjà menée sur ce thème, les données recueillies et analysées révèlent des complexités et des hybridismes dans la répartition des soins, ainsi que des inégalités de classe sociale et de genre. En outre, pour les proches aidants interrogés, la manière préférée/idéale de répartition des soins consiste à combiner les soins apportés par la famille et l'aide à domicile ("ami du soignant proche", dont les interventions peuvent durer jusqu'à huit heures par jour, voire plus). La pertinence de ces résultats, non seulement du point de vue sociologique, mais aussi des points de vue des pratiques professionnelles et des politiques sociales, est discutée en profondeur.

Mots-clés personnes âgées, répartition des soins, aide à domicile, politiques sociales.

La división de los cuidados sociales prestados a personas enfermas: complejidades, desigualdades y preferencias

Este artículo, basado en una investigación cualitativa, informa de la división de la provisión de cuidados sociales a personas enfermas entre cuidadores familiares y cuidadores no familiares. A partir de un modelo conceptual que evita las dicotomías usadas por la investigación anterior sobre este tema, los datos recabados y analizados revelan complejidades e hibridismos en la división de los cuidados, así como desigualdades de clase social y de género. Además de esto, los cuidadores familiares entrevistados eligen la combinación de cuidados familiares con apoyo domiciliario "amigo del cuidador familiar" (cuyas intervenciones puedan ir hasta ocho o más horas por día) como la forma preferida/ideal de división de los cuidados. La relevancia de estos resultados, no sólo desde el punto de vista sociológico, si no también desde los puntos de vista de las prácticas profesionales y de las políticas sociales, es discutida a profundidad.

Palabras-clave personas enfermas, división de los cuidados, apoyo domiciliario, políticas sociales. 